\title{
Differential response of growth and photosynthesis in diverse cotton genotypes under hypoxia stress
}

\author{
R. PAN*, W. JIANG*, Q. WANG ${ }^{*}$, L. XU*, S. SHABALA**, and W.Y. ZHANG*,+ \\ Research Center of Crop Stresses Resistance Technologies/School of Agriculture, Yangtze University, \\ 434025 Jingzhou, China* \\ Tasmanian Institute for Agriculture, University of Tasmania, Private Bag 54, 7001 Hobart, Tasmania, Australia**
}

\begin{abstract}
The objectives of the present study were to compare the dynamic of the growth and photosynthetic characteristics of cotton varieties contrasting in waterlogging (WL) tolerance when subjected to hypoxia stress. The growth of the WL-sensitive genotypes was notably inhibited by WL, mainly as a result of a significant reduction in the net photosynthesis $\left(P_{\mathrm{N}}\right)$ after two days of hypoxia treatment; in the tolerant varieties, no significant changes in $P_{\mathrm{N}}$ were observed until $8 \mathrm{~d}$ after hypoxia onset. The intercellular $\mathrm{CO}_{2}$ concentration and maximal photochemical efficiency of PSII significantly declined, and the nonphotochemical quenching increased in the sensitive varieties. Infrared thermography showed that a low stomatal conductance resulted in an increased leaf temperature under hypoxia stress. Spectral image analysis suggested that the pigment content and water content rapidly decreased in the leaves of the sensitive varieties. It is concluded that maintaining stomatal opening through the interaction of ethylene and abscisic acid may be an important strategy to improve waterlogging tolerance in cotton.
\end{abstract}

Additional key words: chlorophyll fluorescence; Gossypium hirsutum; hyperspectral image; infrared thermal image.

\section{Introduction}

Waterlogging (WL) is a major environmental stress that is commonly caused by a heavy rain or an improper irrigation (Irfan et al. 2010). Approximately one billion hectares suffer from WL worldwide, which results in a massive crop growth inhibition and yield losses (Ahmed et al. 2013, Najeeb et al. 2015). The production of cotton, the most important fibre crop, is strongly affected during its growth period by a large amount of rainfall during the rainy season (Setter and Waters 2003, Bange et al. 2004), particularly in south-eastern Asia and Australia. WL is especially harmful to the quality and yield of cotton because of weak adaptability of cotton to WL (Bange et al. 2004, Zhang et al. 2017), especially, at the seedling stage when cotton has a lower water requirement (Qin et al. 2012).

The damage to plants caused by WL mainly comes from a lack of oxygen (hypoxic or anoxic stress), impaired nutrition, and the accumulation of toxic secondary metabolites and nutrients (Shabala 2011, Araki and Hossain 2012, Jitsuyama 2015). Hypoxia, the most direct and rapid adverse factor, imposes a major restriction on photosynthesis (Armstrong et al. 2009, Bansal and Srivastava
2015). Previous studies demonstrated that photosynthesis parameters were reduced by WL in many crops, such as rice (Winkel et al. 2014, Anandan et al. 2015), wheat (Shao et al. 2013), maize (Ren et al. 2016, Zhu et al. 2016), and pigeon pea (Bansal and Srivastava 2015). The factors affecting the photosynthetic rate are mainly divided into two types: stomatal and nonstomatal inhibition (Alamin et al. 2018). Firstly, $\mathrm{CO}_{2}$ deficiency is the rate-limiting factor for photosynthesis because of stomatal closure (Anandan et al. 2015, Alamin et al. 2018). Additionally, long-term WL results in a severe damage to chloroplast structure and function, representing a nonstomatal component. The harmful substances produced by anaerobic respiration, such as ethanol and acetaldehyde, reduce the activity of oxidation-protective enzymes. Another source of inhibition is elemental toxicity resulting from the shift in the redox potential in flooded soils and an associated increase in concentration of biologically available Fe and Mn (Zeng et al. 2013). Accumulation of malondialdehyde (MDA) relates to development of oxidative stress which is part of the plant response to different environmental stresses (Živčák et al. 2016). The chloroplast degradation caused by reactive oxygen species (ROS) leads to a decrease in the electron transport rate and phosphorylation.

\footnotetext{
Received 26 January 2186, accepted 15 May 2019.

${ }^{+}$Corresponding author; e-mail: wyzhang@yangtzeu.edu.cn

Abbreviations: $C_{\mathrm{i}}$ - intercellular $\mathrm{CO}_{2}$ concentration; $E$ - transpiration rate; $\mathrm{F}_{\mathrm{v}} / \mathrm{F}_{\mathrm{m}}-$ optimal $/$ maximal quantum yield of PSII; $g_{\mathrm{s}}-$ stomatal conductance; NDWI - normalized difference water index; NPQ - nonphotochemical quenching coefficient; $P_{\mathrm{N}}$ - net photosynthetic rate; PSSRa - pigment ratio index $\mathrm{a} ; \mathrm{q}_{\mathrm{p}}$ - photochemical quenching coefficient.

Acknowledgement: We appreciate the contribution of C. Li and Y.W. Nong on experimental execution. We thank to The National Natural Science Fund (No. 31471496) for financial support.
} 
In this context, chlorophyll (Chl) fluorescence parameters are efficient indicators of the transport of light energy and electrons in PSII and can therefore be used as a measure of the WL impact on leaf photochemistry (Dias et al. 2018).

Infrared thermal imaging is regarded as a nondestructive and real-time detection technology for crop temperature and is widely used in studies on abiotic stress, such as drought (Prashar and Jones 2016, Biju et al. 2018) and salt stress (Siddiqui et al. 2014). Infrared thermal imaging was used to identify drought-tolerant lentil genotypes, validating it as a high-throughput screening tool in plants (Biju et al. 2018). In addition, the thermal imaging was proven to be a reliable method for water deficit diagnosis by measuring the canopy temperature (Xu et al. 2015). Hyperspectral imaging, another nondestructive technique, is widely used in agriculture (Lowe et al. 2017). It could measure the reflectivity of light at different wavelengths and thus be used to calculate the water content, cell structure, pigment content, and nitrogen content in plant leaves (Corti et al. 2017, Sytar et al. 2017). Compared to traditional detection methods, infrared thermal imaging and hyperspectral imaging technologies are quicker, more efficient, and more accurate (Lowe et al. 2017, Biju et al. 2018).

Given the fact that adaptive responses of plants to adverse environments have a clearly pronounced timedependence, the nondestructive technology provides a great opportunity for continuous monitoring of morphological and physiological changes in plants under abiotic stresses (Siddiqui et al. 2015, Luan et al. 2018). In the early stage of rhizosphere anoxia, the 1-aminoacyl cyclopropane-1-carboxylic acid (ACC) content increases, which is regarded as the primary signal generated in root tips that is then transferred to other parts of the plant. Subsequently, ACC synthesises ethylene and induces aerenchyma and adventitious root formation in many species (including wheat and rice). As the WL stress continues, the ethylene signal is delivered to the leaves, which upregulates the abscisic acid (ABA) content (Ahmed et al. 2006) and results in a stomatal closure. Although it reduces the transpiration rate and prevents dehydration in leaves, low intercellular $\mathrm{CO}_{2}$ concentration limits the photosynthetic rate, and the accumulation of organic matter in plants decreases (Irfan et al. 2010). At the same time, low oxygen in the root cells quickly stimulates the anaerobic respiratory pathway, which may cause accumulation of ethanol and acetaldehyde. The activities of some important enzymes in the oxidation defence system (such as superoxide dismutase, catalase, etc.) are inhibited, disrupting the balance of the ROS production and detoxification in plants. The rapid increase in the ROS (including $\mathrm{H}_{2} \mathrm{O}_{2}, \mathrm{O}_{2}{ }^{-}$, ${ }^{\circ} \mathrm{OH}$, and $\mathrm{NO}$ ) content does not only destroys the cell membrane and reduces the transport capacity of substances but also affects the activity of many metabolic enzymes, resulting in the blockage of various metabolic pathways in plants (Bansal and Srivastava 2012). Eventually, some morphological changes occur after a long period of flooding. Obviously, the plant response to WL stress is complicated and continuous, prompting a need for different research methods to study it at different time points.

At present, the photosynthesis of cotton under WL stress has been partially studied, but more details about growth and physiological responses deserve attention, particularly WL resistance differences between genotypes and timescale responses after waterlogging. In the current study, a low-oxygen hydroponic system was used to measure responses of three hypoxia-tolerant and three hypoxiasensitive cotton varieties exposed to hypoxia stress. The dynamic responses of morphology, photosynthesis, Chl fluorescence, and leaf temperature were measured. Hyperspectral images were taken in order to reveal the differences between cotton genotype traits and treatment duration and provide a theoretical basis for the improvement of cotton breeding and resistance to WL stress.

\section{Materials and methods}

Plant growth and treatment: The study was carried out at the College of Agriculture, Yangtze University, Hubei, China $\left(112^{\circ} 15^{\prime} \mathrm{N}, 30^{\circ} 36^{\prime} \mathrm{E}\right)$, in 2017 . Six cotton accessions were used as a plant material in the experiment, including three sensitive varieties (S) (Lu37, Wang18, and Zao29) and three tolerant varieties (T) (Cx094, T11-40, and HZ91217). The seeds of the six cotton varieties were soaked in a tap water for $4 \mathrm{~h}$, placed onto a 96-well seedling plate filled with moist fine sand, and placed in a growth room $\left(28^{\circ} \mathrm{C}, 60 \% \mathrm{RH}\right.$, dark) for germination. At the twoleaf stage, uniformly germinated seedlings from each variety were transplanted to Hoagland nutrient solution in a hydroponic box $(160 \times 110 \times 100 \mathrm{~cm})$. Optimal aeration was provided for $2 \mathrm{~d}$ by an air pump as the plants adapted to the hydroponics. For the hypoxia treatment, the solution oxygen content was maintained at $2.0 \mathrm{mg} \mathrm{L}^{-1}$ with an automatic dissolved oxygen metre (Quantum, USA) by the discontinuous bubbling of $\mathrm{N}_{2}$ gas. For the control, the solution oxygen was kept above $7.5 \mathrm{mg} \mathrm{L}^{-1}$ by an air pump. The experiment was carried out in May, and mean temperature was $22-26^{\circ} \mathrm{C}$, RH was between $55-65 \%$. The experiment was replicated three times.

Measurement indices: Plant height $(\mathrm{cm})$, stem diameter $(\mathrm{mm})$, leaf area $\left(\mathrm{cm}^{2}\right)$, and root length $(\mathrm{cm})$ were measured by taking pictures and then analysed by Image $J$ software. Chl metre values (SPAD-502 Plus, Japan), photosynthesis parameters, Chl fluorescence parameters, leaf temperature, and spectral parameters were evaluated at $0,2,4,6$, and $8 \mathrm{~d}$ after hypoxia treatment.

The $L i-6400$ ( $L i$-Cor, USA) was used for the measurements of the net photosynthetic rate $\left(P_{\mathrm{N}}\right)$, stomatal conduc-tance $\left(g_{\mathrm{s}}\right)$, intercellular $\mathrm{CO}_{2}$ concentration $\left(C_{\mathrm{i}}\right)$, and transpiration rate $(E)$ with the following parameters: light intensity of $1,000 \mu \mathrm{mol}$ (photon) $\mathrm{m}^{-2} \mathrm{~s}^{-1}$ provided by a built-in LED light source, flow rate of $450 \mathrm{~mL} \mathrm{~s}^{-1}$, and $\mathrm{CO}_{2}$ concentration of $500 \mu \mathrm{mol} \mathrm{mol}{ }^{-1}$. Measurements were taken on the third leaf from the top between 10:30-12:30 h.

The Chl fluorescence parameters were measured on the third leaf (counting from the top) using a Chl fluorometer (Mini-PAM, Walz, Germany). The initial fluorescence yield $\left(\mathrm{F}_{\mathrm{v}} / \mathrm{F}_{\mathrm{m}}\right)$ was collected after $30 \mathrm{~min}$ of dark treatment. The 
photochemical quenching $\left(\mathrm{q}_{\mathrm{p}}\right)$ and the nonphotochemical quenching (NPQ) were determined after $30 \mathrm{~min}$ of light treatment.

Infrared thermography images were recorded with a thermal imager equipped with a detector (VarioCAM $h r 780$, InfraTec, Germany) using a standard infrared lens with a field of view of $23 \times 17^{\circ}$, a thermal sensitivity of less than 0.05 , and an emission rate of 0.95 . A transmittance of $75 \%$ shade net was hung on the roof to maintain light uniformity. The lens was perpendicular to the top of the third leaf and was $0.5 \mathrm{~m}$ away from the leaves.

Leaf reflection curves were collected from the third leaf by a spectrometer (Field Spec 4, ASD, USA) with a spectral range of $350-2,500 \mathrm{~nm}$. The spectral resolution was 3 and $700 \mathrm{~nm}$. The average value calculated from three readings of each leaf was regarded as valid. The Chl index (PSSRa) and water index (NDWI) were calculated with the following formulas: PSSRa $=\mathrm{R}_{800} / \mathrm{R}_{680}$ (le Maire et al. 2004), $\mathrm{NDWI}=\left(\mathrm{R}_{860}-\mathrm{R}_{1240}\right) /\left(\mathrm{R}_{860}+\mathrm{R}_{1240}\right)($ Galvão et al. 2005).

Statistical analysis: The experimental data were subjected to analysis of variance (ANOVA) by SPSS 22.0 software and Excel 2010, and figures were drawn with SigmaPlot 10.0 software. A completely randomized design (CRD) with three replications was used in this study.

\section{Results}

Morphological response: Plant height decreased significantly compared with control in the sensitive genotypes under hypoxia conditions, especially within the first $2 \mathrm{~d}$. However, plant height was almost identical between controls and hypoxia treatment in tolerant genotypes (Fig. 1A). Similar trends were observed for the stem diameter and leaf area of the sensitive plants (Zao22, Lu37, and Wang18), which decreased by $19.2,18.5$, and $20.2 \%$ compared with those of the control plants, respectively (Fig. $1 B, C$ ). A large number of lateral roots was formed in the tolerant plants under hypoxia stress, resulting in a significant increase in the total root length (2.24 fold of control), while this parameter decreased slightly in the sensitive plants (Fig. 1D). The results suggested that under hypoxia conditions, the tolerant cotton variety grew faster than the sensitive cotton variety, although all six cotton varieties showed the inhibited growth.

Photosynthetic traits: $P_{\mathrm{N}}$ decreased in both the tolerant and sensitive genotypes under hypoxia conditions, and the decrease was more significant in the sensitive plants (55.5, 62.1, and 54.1\% in Zao22, Lu37, and Wang 18, respectively) than that in the tolerant plants $(28.8,12.2$, and $39.8 \%$ in Cx094, T11-40, and HZ91217, respectively) (Fig. 2A). After treatment for $8 \mathrm{~d}, C_{\mathrm{i}}$ decreased by 28.0, 26.1, and $31.3 \%$ in Zao22, Lu37, and Wang 18 , respectively, and by 18.1, 16.7, and 14.0\% in Cx094, T11-40, and HZ91217, respectively (Fig. $2 B$ ). Similarly, $g_{\mathrm{s}}$ decreased significantly after treatment for $8 \mathrm{~d}(61.6,61.3$, and $72.4 \%$ in Zao22, Lu37, and Wang18, respectively). The decrease between 0 to $4 \mathrm{~d}$ was more significant than the decrease between 4 and $8 \mathrm{~d}$. However, $g_{\mathrm{s}}$ decreased slightly in the tolerant plants $(39.1,35.0$, and $29.1 \%$ in Cx094, T11-40, and HZ91217, respectively) after treatment for $8 \mathrm{~d}$, and the decrease intensified from 4 to $8 \mathrm{~d}$ (Fig. $2 C$ ). In the sensitive genotypes, the $E$ decrease was higher from 0 to $4 \mathrm{~d}$ than that from 4 to $8 \mathrm{~d}$, while in the tolerant genotypes, $E$ increased slightly from 0 to $2 \mathrm{~d}$ and decreased by $18.8,19.3$, and $23.1 \%$ in $\mathrm{Cx} 094$, T11-40, and HZ91217, respectively, from 2 to $8 \mathrm{~d}$.

Chl fluorescence parameters: $F_{v} / F_{m}$ and $q_{p}$ decreased significantly in sensitive Zao22, Lu37, and Wang18

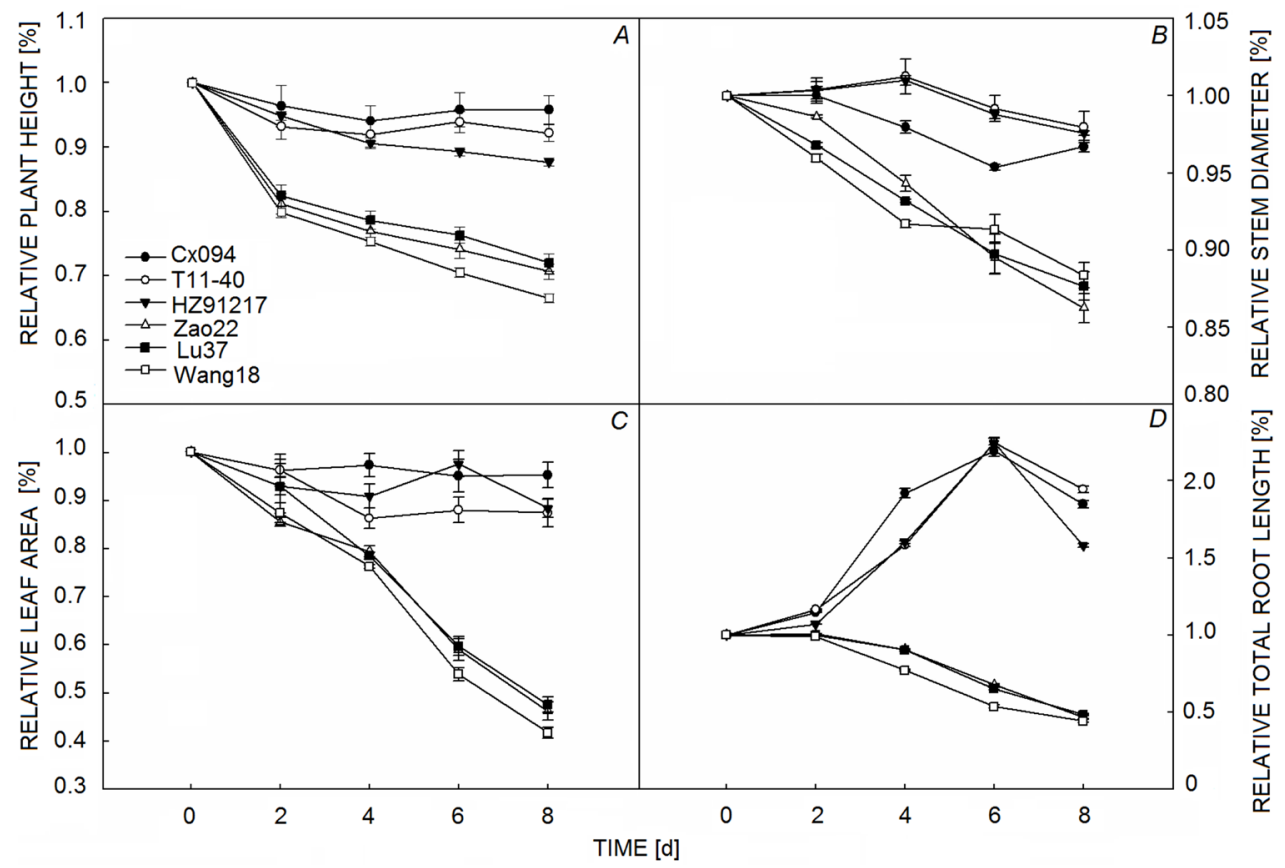

Fig. 1. Morphological index of six cotton varieties under hypoxia stress. $(A)$ plant height, $(B)$ stem diameter, $(C)$ leaf area, and $(D)$ total root length. $y$-axis stands for hypoxia resistance index: HRI $[\%]$ = value of hypoxia/value of control.

Values are means $\pm \operatorname{SD}(n=30)$. Lu37, Wang18, Zao29 - WLsensitive varieties; Cx094, T11-40, HZ91217 - WL-tolerant varieties. 


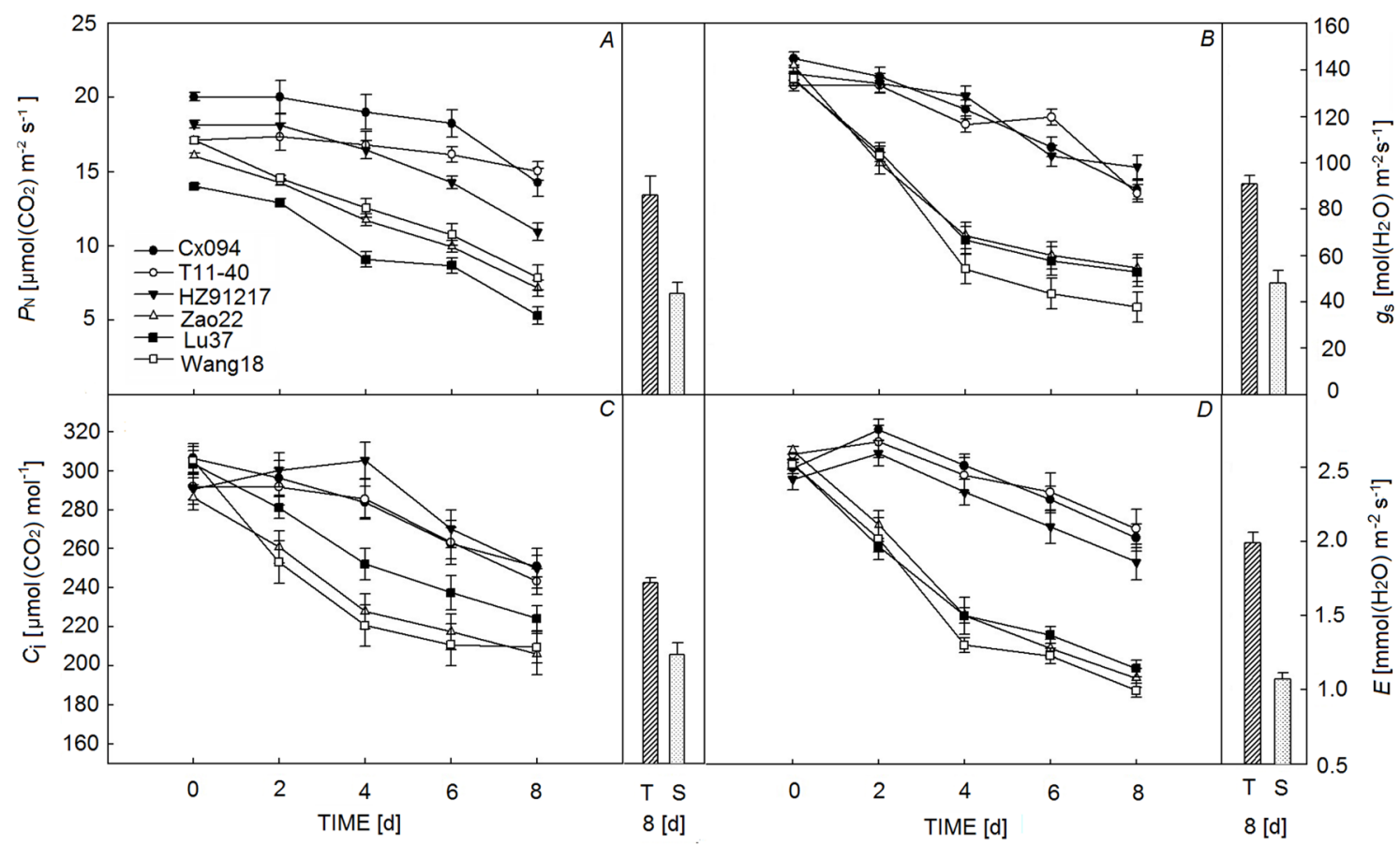

Fig. 2. Photosynthetic characteristics of six cotton varieties under hypoxia stress. $(A)$ net photosynthetic rate $\left(P_{\mathrm{N}}\right),(B)$ intercellular $\mathrm{CO}_{2}$ concentration $\left(C_{\mathrm{i}}\right),(C)$ stomatal conductance $\left(g_{\mathrm{s}}\right)$, and $(D)$ transpiration rate $(E)$. The small bar-chart is the mean of WL-sensitive $(\mathrm{S})$ and tolerant $(\mathrm{T})$ cotton varieties on the $8^{\text {th }} \mathrm{d}$ of hypoxia stress. Values are means $\pm \mathrm{SD}(n=30)$. Lu37, Wang18, Zao29- WL-sensitive varieties; Cx094, T11-40, HZ91217 - WL-tolerant varieties.

genotypes between 2 and $8 \mathrm{~d}$ after hypoxia treatment, while there were no obvious changes in tolerant $\mathrm{Cx} 094$, T11-40, and HZ91217 (Fig. 3A,B). These results indicated that the tolerant varieties had stronger electron transfer activities and light energy-utilization abilities. NPQ showed no changes from 0 to $4 \mathrm{~d}$ and increased slightly from 4 to $8 \mathrm{~d}$ in Cx094, T11-40, and HZ91217, while it increased significantly from 0 to $4 \mathrm{~d}$ in Zao22, Lu37, and
Wang18 (Fig. 3C). Interestingly, NPQ was significantly reduced in only Wang 18 from 4 to $8 \mathrm{~d}$. More energy was lost as a thermal energy in the sensitive plants than that in the tolerant plants, which may be an important factor for growth inhibition.

SPAD value: To compare the $\mathrm{Chl}$ content in the different cotton genotypes after hypoxia stress, the SPAD value

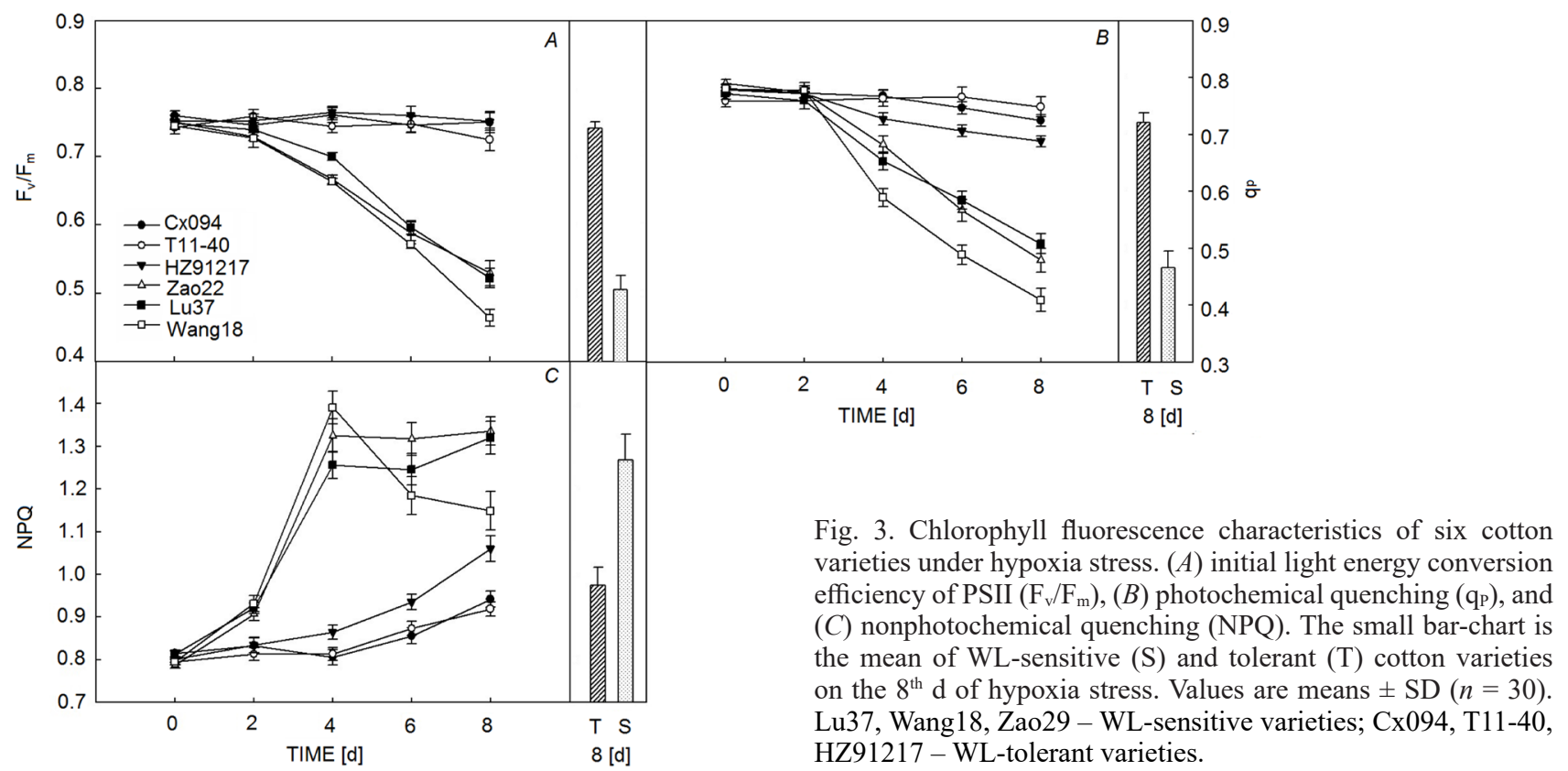




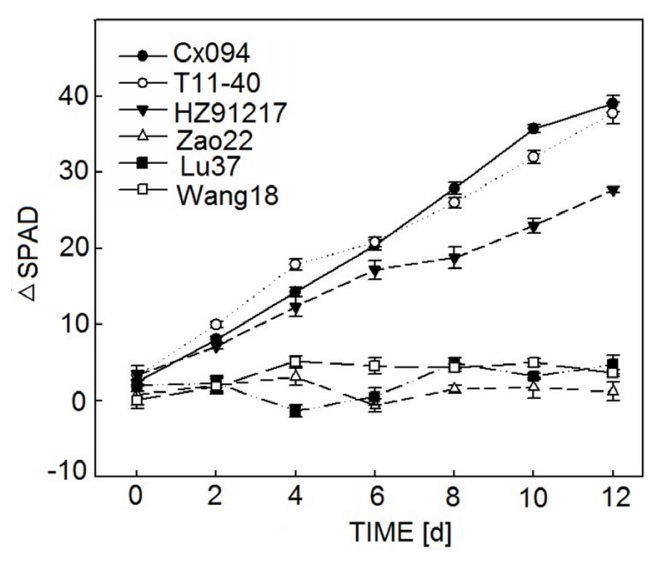

Fig. 4. SPAD value of six cotton varieties under hypoxia stress. $\triangle \mathrm{SPAD}=$ value of control - value of hypoxia. Values are means $\pm \mathrm{SD}(n=30)$. Lu37, Wang18, Zao29 - WL-sensitive varieties; Cx094, T11-40, HZ91217 - WL-tolerant varieties.

was evaluated (Fig. 4). $\triangle$ SPAD (decrease of relative Chl content) rapidly increased in sensitive Zao22, Lu37, and Wang18, 15.9, 11.5, and 8.2 times, respectively, from 0 to $12 \mathrm{~d}$, which could indicate that the Chl content was significantly reduced in these three cotton varieties; however, $\triangle$ SPAD decreased slightly from 2 to $4 \mathrm{~d}$ and recovered from 4 to $8 \mathrm{~d}$ in tolerant Cx094, T11-40, and HZ91217.

Leaf temperature: Metabolic reactions in leaves can cause changes in the leaf temperature (Fig. 5B). The leaf temperature increased in WL-sensitive Zao22, Lu37, and Wang 18 from 6 to $24 \mathrm{~h}$. However, it decreased from 0 to $6 \mathrm{~h}$ and then increased again from 6 to $24 \mathrm{~h}$ in tolerant Cx094, T11-40, and HZ91217. Furthermore, leaf temperature was higher in the sensitive genotypes than that in the tolerant genotypes after WL, which means that the tolerant plants could maintain a stable metabolic environment to avoid anoxia stress damage in the roots.

The leaf reflection curve: There were two troughs from the $480-500 \mathrm{~nm}$ band and the $680-700 \mathrm{~nm}$ band caused by strong light absorption by Chl. In comparison to the tolerant (T) plants, the leaf reflection in the sensitive (S) plants was higher in the two troughs under anaerobic stress, which means that the light absorption was reduced more significantly in $\mathrm{S}$ than that in $\mathrm{T}$ after hypoxia treatment. Furthermore, the two troughs from 1,450-1,500 nm and $1,950-2,000 \mathrm{~nm}$ were regarded as related to the absorption of water by the cell. Usually, leaf reflection decreases when the water content increases. The leaf reflections of the $\mathrm{S}$ plants were higher than those of the $\mathrm{T}$ plants after hypoxia treatment, which showed that water content was lower in the $\mathrm{S}$ plants than that in the T plants (Fig. 6A). The PSSRa rapidly decreased from 0 to $2 \mathrm{~d}$ and then remained low from 2 to $8 \mathrm{~d}$ in sensitive Zao22, Lu37, and Wang18 after hypoxia treatment. In contrast, the PSSRa decreased slowly in tolerant Cx094, T11-40, and HZ91217 from 0 to $6 \mathrm{~d}$ (Fig. $6 B$ ). The change of the NDWI value showed a trend consistent with PSSRa (Fig. 6C). Overall, both the $\mathrm{Chl}$ and water contents decreased in both the $\mathrm{T}$ and $\mathrm{S}$ cotton plants, but this decrease was more significant and quick in the $\mathrm{S}$ plants under hypoxia treatment.

\section{Discussion}

When plants suffer from waterlogging stress, a root system is directly exposed to hypoxia conditions, and is therefore at the first line of defense. It was reported that rapid increase of ACC content was an early signal in plants responding to waterlogging. Ethylene induces the biosynthesis of auxin and directs auxin toward elongation zone, which in turn promotes local auxin increase that inhibits cell elongation in roots (Basu et al. 2011, Ali and Kim 2018). However, the interaction between ethylene and auxin can also regulate the formation of lateral roots and adventitious roots, but the mechanism is not completely clear so far (Basu et al. 2011, Pedersen et al. 2017). In this study, the roots of WL-tolerant plants grew faster than that of WL-sensitive plants, which would lead to the expansion of the root surface area to diffuse oxygen into the roots in WL-tolerant plants. Here, lateral root formation from primordial root and aerial root production were observed in WL-tolerant plants, which may be induced by ethylene regulation. In addition, ethylene has also been reported to be associated with the formation of aerenchyma (Yamauchi et al. 2014, 2016).

Leaf wilting due to water loss is the earliest observed
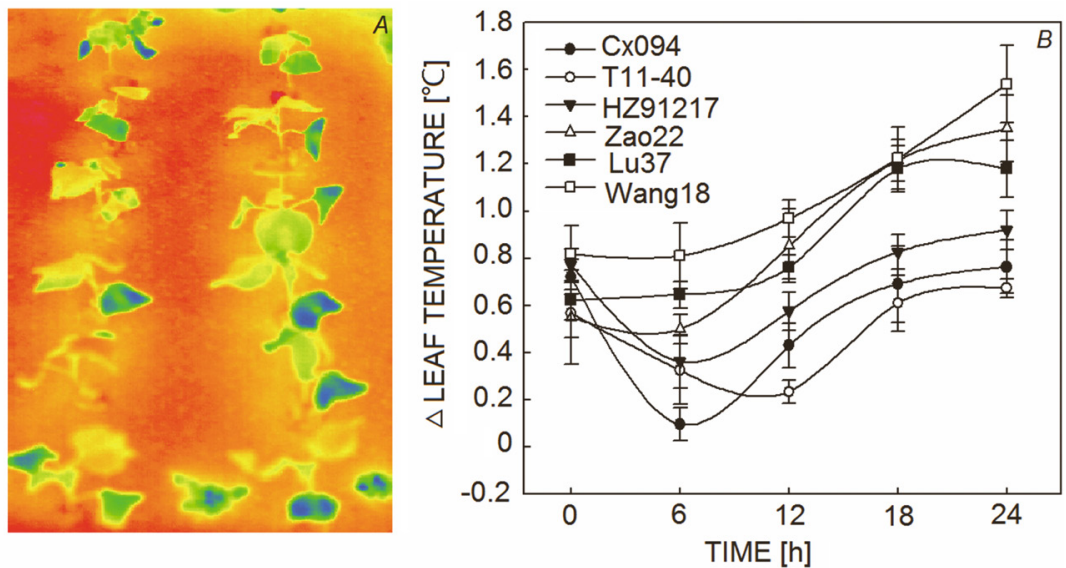

Fig. 5. Real-time leaf temperature of six cotton varieties under hypoxia stress. $(A)$ Infrared thermal imaging and $(B)$ leaf temperature dynamic changes. $\triangle$ Leaf temperature $=$ leaf temperature - environment temperature. Values are means $\pm \mathrm{SD}(n=15)$. Lu37, Wang18, Zao29 - WL-sensitive varieties; Cx094, T11-40, HZ91217 - WLtolerant varieties. 

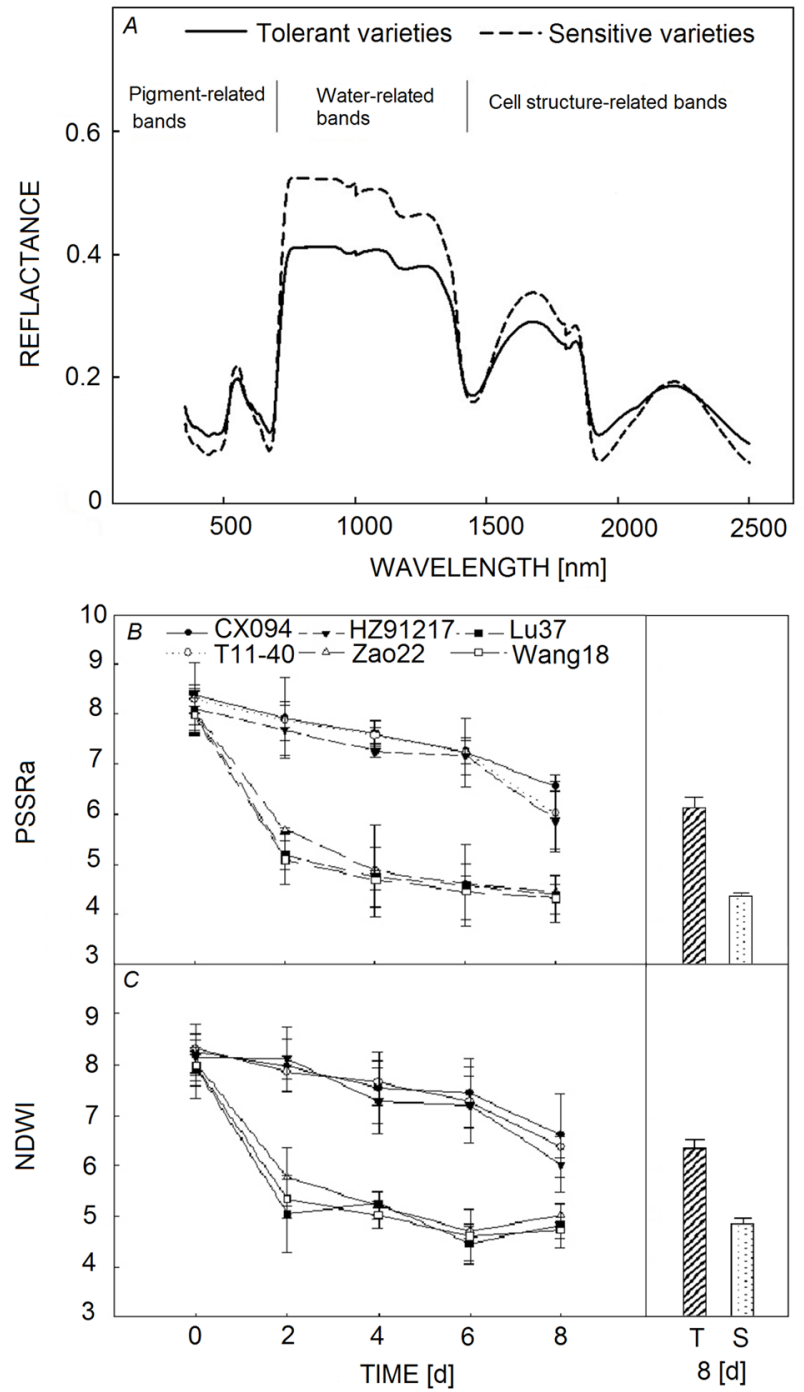

Fig. 6. Spectral reflectance of six cotton varieties under hypoxia stress. (A) Characteristic interval of leaf reflectance in both tolerant $(\mathrm{T})$ and sensitive $(\mathrm{S})$ variety. $(B)$ Pigment ratio index a (PSSRa) value. $(C)$ Normalized difference water index (NDWI) value. The small bar-chart is the mean of $\mathrm{S}$ and $\mathrm{T}$ cotton varieties on the $8^{\text {th }} \mathrm{d}$ of hypoxia stress. Values are means $\pm \mathrm{SD}(n=15)$. Lu37, Wang18, Zao29 - WL-sensitive varieties; Cx094, T11-40, HZ91217 - WL-tolerant varieties.

symptom in the aboveground part of the plant. The reasons are complex and varied, such as a reduction of water otential gradient between the roots and the external environment and aquaporin gating (Gill et al. 2018). Leaf wilting degree and NDWI index showed that leaf water loss was more serious in WL-sensitive plants. Firstly, water is a participant in photosynthesis and other metabolic reactions, and dehydration would directly inhibit photosynthesis and other metabolic reactions. Moreover, previous studies suggested that the decrease of leaf water content leads to the increase of ABA content to induce stomatal closure by regulating $\mathrm{K}^{+}$and anions channels (Jiang et al. 2014, Kurepin et al. 2015, Ha et al. 2016, Brodribb and McAdam 2017). However, ethylene had a negative effect on stomatal closure induced by ABA (She and Song 2012,
Chen et al. 2013, Pedersen et al. 2017, Najeeb et al. 2018). In our results, $g_{\mathrm{s}}$ was significantly reduced in WL-sensitive plants, indicating that plants closed their stomata as a stress response to water loss. On the contrary, tolerant plants can maintain leaf moisture adequate and stomata are opening in the early stage of flooding, and the $g_{\mathrm{s}}$ index is almost unchanged.

Stomatal closure prevents gas exchange between leaves and air, and $C_{\mathrm{i}}$ decreases rapidly, which results in the main rate-limiting factor of photosynthesis in the early phase of hypoxia stress (Issarakraisila et al. 2007, Ren et al. 2016). This is the main reason for the rapid decline of photosynthetic rate in WL-sensitive plants and the constant photosynthetic rate in WL-tolerant plants in the early stage of hypoxia stress. But after a long time of hypoxia treatment, the decrease of $F_{v} / F_{m}$ and $q_{p}$ suggested that the PSII reaction centers were largely damaged and closed possibly because ROS accumulation destroyed the chloroplast structure and photosynthetic enzymes (Cherif et al. 2010, Wu et al. 2015, Keller et al. 2019). Here, the limitation of maximal photochemical efficiency could be explained by SPAD and spectral curve characteristic parameters. The correlation coefficient of $F_{v} / F_{m}$ and SPAD was 0.87 , indicating that chloroplast degradation plays the most important role in $\mathrm{F}_{\mathrm{v}} / \mathrm{F}_{\mathrm{m}}$ decline. Many hyperspectral indexes based on reflectivity from 480 to $700 \mathrm{~nm}$, such as PSSRa, PSSRb, TCARI, NDVI, msR $_{705}$, etc., had been reported to be highly correlated with the Chl content. In this study, the correlation coefficient between SPAD and PSSRa was 0.793 (not shown), and both these two parameters could accurately represent the $\mathrm{Chl}$ content in leaves. Both SPAD and PSSRa suggested that the Chl content decreased significantly in the WL-sensitive cotton varieties after hypoxia treatment. Moreover, there was negative regulation of photosynthetic rate because active transport of photosynthetic products was inhibited by membrane oxidation and ATP deficiency (Li et al. 2011) and activity of photosynthesis-related enzymes was reduced (Pandey et al. 2000). NPQ increased significantly in WL-sensitive cotton varieties, which indicated that the optical energy absorbed by the pigments was converted into heat energy and lost under hypoxia stress.

The LT increasing can be explained in two aspects. Most important, stomatal closure restrains heat dissipation by transpiration. Besides, more light energy is converted into heat energy in leaves. In this study, LT increased significantly compared with that of control in the early phase of hypoxia stress in WL-sensitive cotton varieties. Although it has been reported that higher temperatures open stomata (Urban et al. 2017), this phenomenon has not been observed in cotton, possibly due to too much water loss to allow stomatal opening. Subsequently, some primary metabolic reactions may be affected, resulting in metabolic disorders and inhibition of plant growth.

The dynamic monitoring of different photosynthesis and $\mathrm{Chl}$ fluorescence parameters could reveal plant growth strategies under waterlogging stress conditions. Under waterlogging stress, $P_{\mathrm{N}}$ was influenced by stomatal activity and $C_{\mathrm{i}}$ in early stage of waterlogging stress, whereas photosynthesis rate is severely inhibited due to 
photosynthetic organ damage in the late flooding stage. Maintaining stomatal opening and leaf temperature stability are important for cotton seedlings to improve waterlogging tolerance.

\section{References}

Ahmed F., Rafii M.Y., Ismail M.R. et al.: Waterlogging tolerance of crops: breeding, mechanism of tolerance, molecular approaches, and future prospects. - Biomed Res. Int. 2013: 963525,2013

Ahmed S., Nawata E., Sakuratani T.: Changes of endogenous $\mathrm{ABA}$ and $\mathrm{ACC}$, and their correlations to photosynthesis and water relations in mungbean (Vigna radiata (L.) Wilczak cv. KPS1) during waterlogging. - Environ. Exp. Bot. 57: 278-284, 2006.

Alamin M., Zeng D.D., Sultana M.H. et al.: Photosynthesis, cellulose contents and ultrastructure changes of mutant rice leading to screw flag leaf. - Plant Growth Regul. 85: 1-13, 2018.

Ali S., Kim W.C.: Plant growth promotion under water: decrease of waterlogging-induced ACC and ethylene levels by ACC deaminase-producing bacteria. - Front. Microbiol. 9: 1096, 2018.

Anandan A., Pradhan S.K., Das S.K. et al.: Differential responses of rice genotypes and physiological mechanism under prolonged deepwater flooding. - Field Crop Res. 172: 153-163, 2015.

Araki H., Hossain M.A., Takahashi T.: Waterlogging and hypoxia have permanent effects on wheat root growth and respiration.J. Agron. Crop Sci. 198: 264-275, 2012.

Armstrong W., Webb T., Darwent M., Beckett P.M.: Measuring and interpreting respiratory critical oxygen pressures in roots. - Ann. Bot.-London 103: 281-293, 2009.

Bange M.P., Milroy S.P., Thongbai P.: Growth and yield of cotton in response to waterlogging. - Field Crop Res. 88: 129-142, 2004.

Bansal R., Srivastava J.P.: Antioxidative defense system in pigeonpea roots under waterlogging stress. - Acta Physiol. Plant. 34: 515-522, 2012.

Bansal R., Srivastava J.P.: Effect of waterlogging on photosynthetic and biochemical parameters in pigeonpea. - Russ. J. Plant Physl+ 62: 322-327, 2015.

Basu P., Brown K.M., Pal A.: Detail quantitative analysis of architectural traits of basal roots of young seedlings of bean in response to auxin and ethylene. - Plant Physiol. 155: 2056-2065, 2011.

Biju S., Fuentes S., Gupta D.: The use of infrared thermal imaging as a non-destructive screening tool for identifying drought-tolerant lentil genotypes. - Plant Physiol. Bioch. 127: $11-24,2018$

Brodribb T.J., McAdam S.A.M.: Evolution of the stomatal regulation of plant water content. - Plant Physiol. 174: 639-649, 2017

Chen L., Dodd I.C., Davies W.J., Wilkinson S.: Ethylene limits abscisic acid- or soil drying-induced stomatal closure in aged wheat leaves. - Plant Cell Environ. 36: 1850-1859, 2013.

Cherif J., Derbel N., Nakkach M. et al.: Analysis of in vivo chlorophyll fluorescence spectra to monitor physiological state of tomato plants growing under zinc stress. - J. Photoch. Photobio. B. 101: 332-339, 2010.

Corti M., Gallina P.M., Cavalli D., Cabassi G.: Hyperspectral imaging of spinach canopy under combined water and nitrogen stress to estimate biomass, water, and nitrogen content. - Biosyst. Eng. 158: 38-50, 2017.
Dias M.C., Correia S., Serôdio J. et al.: Chlorophyll fluorescence and oxidative stress endpoints to discriminate olive cultivars tolerance to drought and heat episodes. - Sci. Hortic.Amsterdam 231: 31-35, 2018.

Galvão L.S., Formaggio A.R., Tisot D.A.: Discrimination of sugarcane varieties in southeastern Brazil with EO-1 Hyperion data. - Remote Sens. Environ. 94: 523-534, 2005.

Gill M.B., Zeng F., Shabala L. et al.: The ability to regulate voltage-gated $\mathrm{K}^{+}$-permeable channels in the mature root epidermis is essential for waterlogging tolerance in barley. J. Exp. Bot. 69: 667-680, 2018.

Ha Y., Shang Y., Nam K.H.: Brassinosteroids modulate ABAinduced stomatal closure in Arabidopsis. - J. Exp. Bot. 67: 6297-6308, 2016.

Irfan M., Hayat S., Hayat Q. et al.: Physiological and biochemical changes in plants under waterlogging. - Protoplasma 241: 3-17, 2010.

Issarakraisila M., Ma Q., Turner D.W.: Photosynthetic and growth responses of juvenile Chinese kale (Brassica oleracea var. alboglabra) and Caisin (Brassica rapa subsp. parachinensis) to waterlogging and water deficit. - Sci. Hortic.Amsterdam 111: 107-113, 2007.

Jiang Y., Wu K., Lin F. et al.: Phosphatidic acid integrates calcium signaling and microtubule dynamics into regulating ABA-induced stomatal closure in Arabidopsis. - Planta 239: 565-575, 2014.

Jitsuyama Y.: Morphological root responses of soybean to rhizosphere hypoxia reflect waterlogging tolerance. - Can. J. Plant Sci. 95: 999-1005, 2015.

Keller B., Vass I., Matsubara S. et al.: Maximum fluorescence and electron transport kinetics determined by light-induced fluorescence transients (LIFT) for photosynthesis phenotyping. - Photosynth. Res. 140: 221-233, 2019.

Kurepin L.V., Ivanov A.G., Zaman M. et al.: Stress-related hormones and glycinebetaine interplay in protection of photosynthesis under abiotic stress conditions. - Photosynth. Res. 126: 221-235, 2015.

le Maire G.L., François C., Dufrêne E.: Towards universal broad leaf chlorophyll indices using PROSPECT simulated database and hyperspectral reflectance measurements. - Remote Sens. Environ. 89: 1-28, 2004.

Li C., Jiang D., Wollenweber B. et al.: Waterlogging pretreatment during vegetative growth improves tolerance to waterlogging after anthesis in wheat. - Plant Sci. 180: 672-678, 2011.

Lowe A., Harrison N., French A.P.: Hyperspectral imag4e analysis techniques for the detection and classification of the early onset of plant disease and stress. - Plant Methods 13: 80-92, 2017.

Luan H., Guo B., Pan Y. et al.: Morpho-anatomical and physiological responses to waterlogging stress in different barley (Hordeum vulgare L.) genotypes. - Plant Growth Regul. 85: 399-409, 2018.

Najeeb U., Bange M.P., Tan D.K.Y., Atwell B.J.: Consequences of waterlogging in cotton and opportunities for mitigation of yield losses. - AoB Plants 7: plv080, 2015.

Najeeb U., Tan D.K.Y., Bange M.P., Atwell B.J.: Protecting cotton crops under elevated $\mathrm{CO}_{2}$ from waterlogging by managing ethylene. - Funct. Plant Biol. 45: 340-349, 2018.

Pandey D.M., Goswami C.L., Kumar B., Jain S.: Hormonal regulation of photosynthetic enzymes in cotton under water stress. - Photosynthetica 38: 403-407, 2000.

Pedersen O., Perata P., Voesenek L.A.C.J.: Flooding and low oxygen responses in plants. - Funct. Plant Biol. 44: 3-6, 2017.

Prashar A., Jones H.G.: Assessing drought responses using thermal infrared imaging. - In: Duque P. (ed.): Environmental Responses in Plants. Methods in Molecular Biology. 
Vol. 1398. Pp. 209-219. Humana Press, New York 2016.

Qin Q., Zhu J., Jia C. et al.: Influence of surface waterlogging on cotton seedlings under high temperature synoptic conditions. Adv. J. Food Sci. Technol. 4: 362-365, 2012.

Ren B., Zhang J., Dong S. et al.: Effects of waterlogging on leaf mesophyll cell ultrastructure and photosynthetic characteristics of summer maize. - PLoS ONE 11: e0161424, 2016.

Ren B., Zhu Y., Zhang J. et al.: Effects of spraying exogenous hormone 6-benzyladenine (6-BA) after waterlogging on grain yield and growth of summer maize. - Field Crop. Res. 188: 96-104, 2016.

Setter T.L., Waters I.: Review of prospects for germplasm improvement for waterlogging tolerance in wheat, barley and oats. - Plant Soil 253: 1-34, 2003.

Shabala S.: Physiological and cellular aspects of phytotoxicity tolerance in plants: the role of membrane transporters and implications for crop breeding for waterlogging tolerance. New Phytol. 190: 289-298, 2011

Shao G.C., Lan J.J., Yu S.E. et al.: Photosynthesis and growth of winter wheat in response to waterlogging at different growth stages. - Photosynthetica 51: 429-437, 2013.

She X.P., Song X.G.: Ethylene inhibits abscisic acid-induced stomatal closure in Vicia faba via reducing nitric oxide levels in guard cells. - New Zeal. J. Bot. 50: 203-216, 2012.

Siddiqui M.H., Al-Khaishany M.Y., Al-Qutami M.A. et al.: Response of different genotypes of faba bean plant to drought stress. - Int. J. Mol. Sci. 16: 10214-10227, 2015.

Siddiqui Z.S., Cho J.I., Park S.H. et al.: Phenotyping of rice in salt stress environment using high-throughput infrared imaging. - Acta Bot. Croat. 73: 312-321, 2014.

Sytar O., Brestič M., Živčák M. et al.: Applying hyperspectral imaging to explore natural plant diversity towards improving salt stress tolerance. - Sci. Total Environ. 578: 90-99, 2017.

Urban J., Ingwers M.W., McGuire M.A., Teskey R.O.: Increase in leaf temperature opens stomata and decouples net photosynthesis from stomatal conductance in Pinus taeda and Populus deltoides $\times$ nigra. - J. Exp. Bot. 68: 1757-1767, 2017.

Winkel A., Pedersen O., Ella E. et al.: Gas film retention and underwater photosynthesis during field submergence of four contrasting rice genotypes. - J. Exp. Bot. 65: 3225-33, 2014.

Wu X.L., Tang Y.L., Li C.S. et al.: Chlorophyll fluorescence and yield responses of winter wheat to waterlogging at different growth stages. - Plant Prod. Sci. 18: 284-294, 2015.

Xu J., Lv Y., Liu X. et al.: Diagnosing crop water stress of rice using infrared thermal imager under water deficit condition. Int. J. Agric. Biol. 18: 565-572, 2015.

Yamauchi T., Tanaka A., Mori H. et al.: Ethylene-dependent aerenchyma formation in adventitious roots is regulated differently in rice and maize. - Plant Cell Environ. 39: 2145-2157, 2016.

Yamauchi T., Watanabe K., Fukazawa A. et al.: Ethylene and reactive oxygen species are involved in root aerenchyma formation and adaptation of wheat seedlings to oxygendeficient conditions. - J. Exp. Bot. 65: 261-273, 2014.

Zeng F., Shabala L., Zhou M. et al.: Barley responses to combined waterlogging and salinity stress: separating effects of oxygen deprivation and elemental toxicity. - Front. Plant Sci. 4: 313, 2013.

Zhang Y., Kong X., Dai J. et al.: Global gene expression in cotton (Gossypium hirsutum L.) leaves to waterlogging stress. PLoS ONE 12: e0185075, 2017.

Zhu M., Li F.H., Shi Z.S.: Morphological and photosynthetic response of waxy corn inbred line to waterlogging. Photosynthetica 54: 636-640, 2016.

Živčák M., Brestič M., Sytar O.: Osmotic adjustment and plant adaptation to drought stress. - In: Hossain M., Wani S., Bhattacharjee S. et al. (ed.): Drought Stress Tolerance in Plants. Vol. 1. Pp. 105-143. Springer, Cham 2016.

(C) The authors. This is an open access article distributed under the terms of the Creative Commons BY-NC-ND Licence. 